\title{
A GENERALIZATION OF THE KALMAN RANK CONDITION FOR TIME-DEPENDENT COUPLED LINEAR PARABOLIC SYSTEMS
}

\author{
F. Ammar Khodja, A. Benabdallah, C. Dupaix And \\ M. GONZÁLEZ-BURGOS
}

\begin{abstract}
In this paper we present a generalization of the Kalman rank condition for linear ordinary differential systems to the case of systems of $n$ coupled parabolic equations (posed in the time interval $(0, T)$ with $T>0)$ where the coupling matrices $A$ and $B$ depend on the time variable $t$. To be precise, we will prove that the Kalman rank condition $\operatorname{rank}[A \mid B]\left(t_{0}\right)=n$, with $t_{0} \in[0, T]$, is a sufficient condition (but not necessary) for obtaining the exact controllability to the trajectories of the considered parabolic system. In the case of analytic matrices $A$ and $B$ (and, in particular, constant matrices), we will see that the Kalman rank condition characterizes the controllability properties of the system. When the matrices $A$ and $B$ are constant and condition $\operatorname{rank}[A \mid B]=n$ holds, we will be able to state a Carleman inequality for the corresponding adjoint problem.
\end{abstract}

Mathematics subject classification (2000): 93B05, 93B07, 35K05, 35K55, 35R30.

Keywords and phrases: Kalman condition, control, observability, Carleman estimates, parabolic systems.

\section{REFERENCES}

[1] F. Ammar Khodja, A. Benabdallah, C. Dupaix, I. Kostin, Controllability to the trajectories of phase-field models by one control force, SIAM J. Control Optim., 42, 5 (2003), 1661-1680.

[2] F. Ammar Khodja, A. Benabdallah, C. Dupaix, Null-controllability of some reaction-diffusion systems with one control force, J. Math. Anal. Appl., 320, 2 (2006), 928-943.

[3] F. Ammar Khodja, A. Benabdallah, C. Dupaix, M. González-Burgos, Controllability for a class of reaction-diffusion systems: generalized Kalman's condition, C. R. Math. Acad. Sci. Paris, 345, 10 (2007), 543-548.

[4] F. Ammar Khodja, A. Benabdallah, C. Dupaix, M. GonzÁlez-Burgos, a Kalman rank condition for the localized distributed controllability of a class of linear parabolic systems, submitted to Comm. PDE.

[5] O. BodArt, M. GonzÁLEZ-Burgos, R. PÉREZ-García, Existence of insensitizing controls for a semilinear heat equation with a superlinear nonlinearity, Comm. PDE, 29, 7-8 (2004), 1017-1050.

[6] J.M. Coron, Control and Nonlinearity, Mathematical Surveys and Monographs, 136, American Mathematical Society, Providence, RI, 2007.

[7] E. FernándeZ-CARA, M. GonZÁLEZ-Burgos, L. DE Teresa, About boundary controllability of cascade heat equations, in preparation.

[8] E. FERNÁNDEZ-CARA, E. ZUAZUA, The cost of approximate controllability for heat equations: The linear case, Adv. Differential Equations, 5 (2000), 465-514.

[9] A. Fursikov, O. Yu. Imanuvilov, Controllability of evolution equations, Lecture Notes Ser. 34, Seoul National University, Korea, 1996.

[10] J.-M. Ghidaglia, Some backward uniqueness results, Nonlinear Anal., 10, 8 (1986), 777-790.

[11] M. GonzÁlez-Burgos, R. PÉREZ-GarcíA, Controllability results for some nonlinear coupled parabolic systems by one control force, Asymptot. Anal., 46, 2 (2006), 123-162.

[12] M. GonZÁLEZ-Burgos, L. DE Teresa, Controllability results for cascade systems of $m$ coupled parabolic PDEs by one control force, submitted. 
[13] S. GUERRERO, Null controllability of some systems of two parabolic equations with one control force, SIAM J. Control Optim., 46, 2 (2007), 379-394.

[14] O. Yu. Imanuvilov, M. Yамамото, Carleman inequalities for parabolic equations in Sobolev spaces of negative order and exact controllability for semilinear parabolic equations, Publ. Res. Inst. Math. Sci., 39, 2 (2003), 227-274.

[15] R. E. Kalman, P. L. FAlb, M. A. ARBiB, Topics in mathematical control theory, McGraw-Hill Book Co., New York-Toronto, Ont.-London 1969.

[16] H. LEIVA, Controllability of a system of parabolic equations with non-diagonal diffusion matrix. IMA J. Math. Control Inform., 22, 2 (2005), 187-199.

[17] L. M. Silverman, H. E. Meadows, Controllability and observability in time-variable linear systems, SIAM J. Control, 5, 1 (1967), 64-73.

[18] L. DE TERESA, Insensitizing controls for a semilinear heat equation, Comm. PDE, 25, 1-2 (2000), $39-72$. 